\title{
THEORETICAL-METHODOLOGICAL CONSIDERATIONS REGARDING THE FORMATION AND STRENGTHENING OF MOTOR SKILLS IN MILITARY PHYSICAL EDUCATION
}

\author{
Robert STĂNCIULESCU \\ „Nicolae Bălcescu“ Land Forces Academy, Sibiu, Roumania \\ rstanciulescu@.armyacademy.ro
}

\begin{abstract}
The programme of training in the field of military physical education is directed towards developing an efficient motor capacity by ensuring superior development gauges for basic motor skills and for the motor skills and aptitudes specific to the military system, as well as towards developing the body resilience to stress, enhancing productivity and the mental alarm state of mind, elements playing an important role in improving the combat capacity. In the economy of the formative process, the basic motor and utility-applicable skills represent the essence of an advanced level of training in the field of physical education, so that their development, strenghening and improvement will always be a constant priority objective of training.
\end{abstract}

Keywords: training, utilitary-applicative skills, consolidation, motivation

\section{Introduction}

The process of training of officers includes among its pillars the physical education, with the set of psychic-physical attitudes, aptitudes, skills and abilities representing the foundation of the evolution in the career and of the efficient exercising of roles and missions assigned in the military organization.

The basic motor and utilityapplicable skills (specific to the sports disciplines included in the syllabus) are formed and consolidated on the basis of a training programme that is rigorously drawn up and carried out.

The planning, organizing, conduct and evaluation of activities specific to accomplishing these objectives are essential elements, having different and clearly defined contributions to the formative process.

Identifying the modalities of improving the methods and procedures by which the objectives related to the formation and strenghtening of motor aptitudes and skills specific to the carrying out of military activities represents a permanent concern for the specialists in the field of physical education and military sports, who are trying to open new ways of reflection and action for their improvement.

\section{Motor and utilitary-applicative skills}

\subsection{Characteristics of motor skills}

There are many definitions with regard to this, but most specialists in the field agree that they represent the result of learning, being formed and consolidated through exercise and becoming automatic reflexes in a conscious way.

In 1976, Mihai Epuran points to the fact that motor skills are components of a voluntary activity which through practice reach a high level of efficiency on the basis of improving the markers of execution (coordination, accuracy, speed, easiness, 
automation). In the behavioural system the motor skills are extremely important since on their basis the results are obtained in the type of activity which is repeated in a certain rhythm.

Representing effects of exercising the motor skills, they are at the same time components of the voluntary condition, consciously formed and trained. Another important characteristic is that, being specific to a motor action, they represent the qualitative results of learning, thus being modes of learned motor behaviour.

They represent structures of coordinated movement, which is part of a whole set based on the education of the body capacity to make differences between the characteristics of the carried out activities. [1] At the same time, the motor skills are characterized by stability and plasticity, being individual structures determined by the variable features and attitudes of the subjects.

The formation, consolidation and improvement of motor skills depends on the following factors:

- motor aptitudes;

- motivation of subjects;

- pedagogical level of instruction;

- appreciation of results;

- self-control;

- number of practical exercises.

Figure number 1 presents the factors influencing the formation, strengthening and improvement of motor skills.

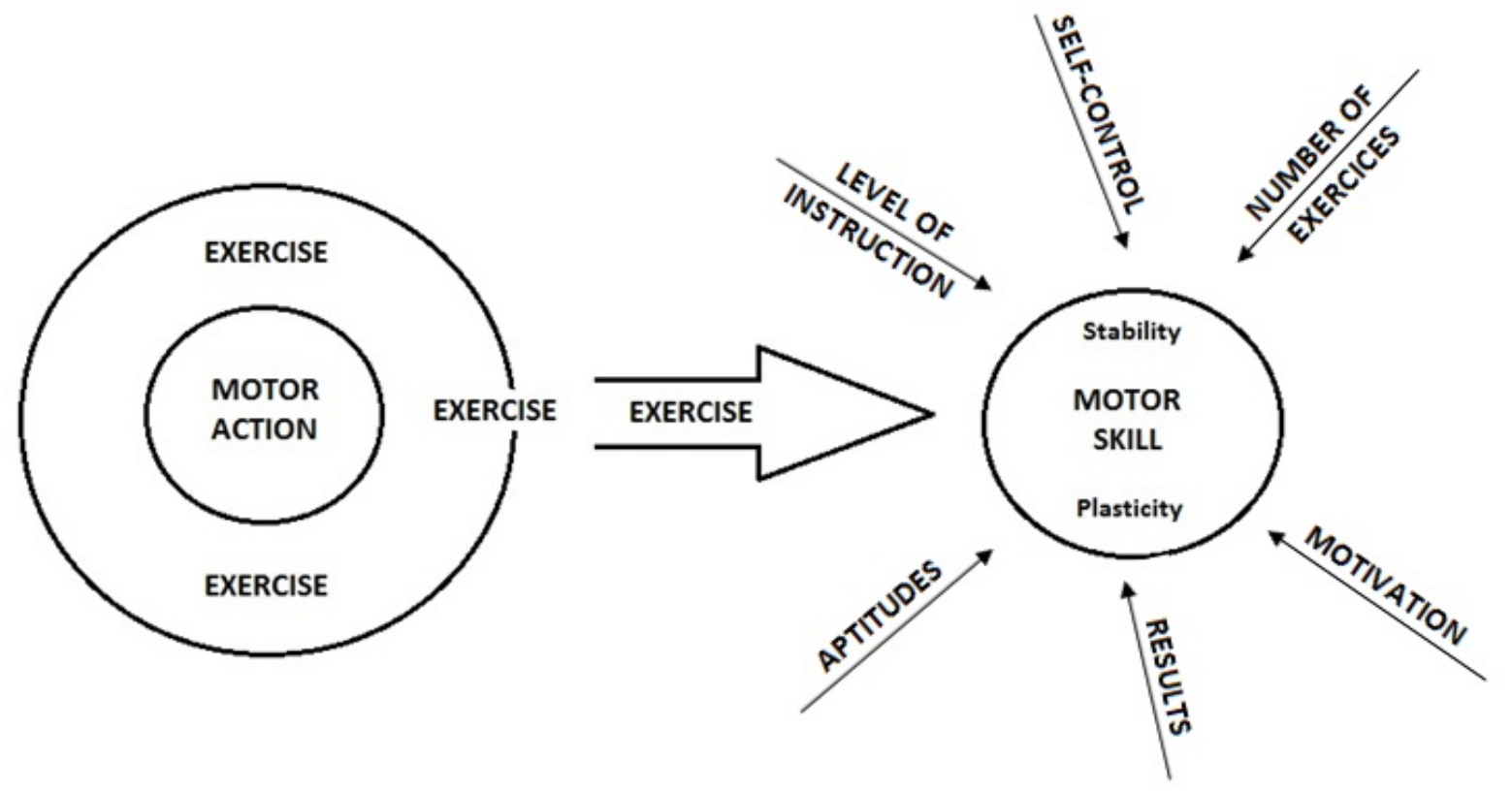

Fig. no. 1 Factors influencing the formation, consolidation and improvement of motor skills

\subsection{Classification of motor skills}

Motor skills can be classified according to a great number of aspects, as follows:

a) According to the sensorial criteria characterizing a certain motor action:

- Motor skills proper representing reactions of the kinesthetic synthesis and being coordinated on the basis of the transmission of excitement from the periphereal receptor neurons to the central neurons relying on the information received with regard to the nature of movements, data derived from the performer's body.

Thus, the kinesthetic analyzer informs the central nervous system about the body and its segments position and movement in space or about the degree of muscle contraction on the basis of the information from some receptors found in the muscles, sinews, joints or ligaments. In this case the transmission of excitement from the peripheral receptor neurons to the 
central neurons is achieved primarily internally and the external perceptive markers represent the elements conditioning the area for performing the movement.

- The perceptive-motor skills which are characterized by the fact that the operational information is achieved among the features of the stimuli or the external markers and the corresponding motor reactions. The main characteristic of this type of skills is that the external factors no longer influence the skill once it is already automatic. They are also known as cognitive-motor skills.

- Intelligent motor skills specific to certain sports disciplines that are carried on as competitions.

b. According to the mode of action, motor skills are divided into:

- Continuous motor skills;

- Discontinuous motor skills.

According to this criterion, the continuous skills have their own normal mode of development, being integrated into the whole.

The discontinuous motor skills are made up of component parts that have their own structures, without being linked between them.

c. According to their structure motor skills are divided into: [2]

- Elementary skills, with complete automation as a main characteristic, having certain peculiarities related to the mode of transmission of the signal. They represent skills which become automatic through sets of movements that are repeated in a unit of time (swimming, skiing etc.).

- Complex skills having the feature of being incomplete and of necessitating blendings of structures combined among themselves.

d. According to their size motor skills are divided into:

- Fine motor skills;

- Intermediary motor skills;

- Big motor skills;
The main feature of these types of motor skills consists in the fact that they have been classified in this way in accordance with the number of muscles, joints and bones involved in the movements performed during the motor actions specific to the respective skills.[3]

e. Also there are other criteria according to which motor skills are divided into overt and covert motor skills, self and hetero conducted, each having specific characteristics.

f.An extremely important criterion divides motor skills according to the mode of utilization. Thus, we can mention:

- General motor skills including primary motor skills (walking, running, jumping, throwing), as well as utilityapplicable skills (climbing, crawling, escalating, weight transportation).

- Tactical skills - that include actional and operational sets specific to the different sports disciplines.

- Technical skills - that represent movements specific to the different sports activities.

\subsection{Didactics of forming and strengthening motor skills specific to military physical education}

It is unanimously acknowledged the fact that at present it is vitally important that fighters be able to adapt to the conditions existing on the integrated battlefield, to combine the intellectual capacities specific to utilizing modern technologies with the physical qualities, skills and abilities that are vital for the action taking place in the most diverse situations to be found on the battlefield.

We must clearly underline the fact that military physical education, as a basic pillar of the formative process, circumscribes important directions of action with a view to ensuring the quality of instruction through the means it makes use of. In this context, it is necessary that along with developing the basic motor qualities, such as speed, resistance and strength, special attention should be given 
to the process of learning-consolidatingperfecting the motor skills, utilityapplicable and sports skills utilized within the process of training. In this way the motor and utility-applicable skills, such as walking, climbing, jumping, crawling, are adjusted to the specific features of the sports disciplines specified in the military physical education syllabus, which are consolidated and perfected in accordance with the structure of the activities specific to performing the actions of armed combat generated by the diversity of missions.

Thus, the components of military physical education are assimilated into the general process of training and the improvement of performance is achieved on the basis of science intervention, which changes the instructional-educational process into activities based on state-ofthe-art technologies.

The motor and utility-applicable skills can be learnt in two ways: as a whole for the elementary, simple skills and on the component parts if the skills are complex. The components of complex motor skills are chosen in such a way that each of them represents a distinctive part of the complex skill.[4]

In order to form the motor skill, it is necessary that the following elements should be observed:

- The explanation with regard to the necessity of acquiring the respective skill, its goal being to develop the interest and stimulate the desire to acquire the skill in the best possible conditions. Another goal is to consciously take part in learning and acquiring the skill.

- Informing and repeating the conditions for the carrying out of the activity, with the goal of understanding the rational motives regarding their necessity.

- Presentation of the standards that must be met, the goal being that of providing a concrete objective.

- It is extremely important that the acquisition of a certain skill be done in conditions as close as possible to the real ones. The particularities of the formed motor skills largely depend on the concrete conditions in which they were formed. Hence the necessity that the component parts of a motor skill of being always performed in the same sequential order, so that the structure of movement may be always the same.

- In order to be efficient and the performers to be confident, the formation of skills must be done under the careful guidance of specialists.

- The correct wording of the operational objectives.

- The appropriate choice of organising forms

The efficient application of the methodology typical to pedagogical engineering.

- methods for work organising

- pedagogical methods

evaluation

- mothods for sequential

- The pedagogical instruments should be useful and efficient.

- The use of available resources in normal parameters.

- The initial acquisition of the motor action must be done slowly.

In accordance with the characteristics of the motor skills, the learning and formation of these skills can be achieved in a combined way or on the component parts.

The method of learning on the component parts is extremely useful in the following situations:

-when the motor action is so complex that learning by the component parts is easier and more useful;

-when the execution of the motor action can integrally cause accidents;

-when the motor action, although seeming to be easy, includes new component parts that are acquired through the hard way;

-if the motor action has several components.

The procedure of acquiring motor actions by the component parts is an efficient procedure having major impact on 
learning the complex and difficult motor actions.

Another advantage of this method is that of allowing for a proper distribution from the point of view of the time for execution, as well as of the number of utilized repetitions in the process of formation.

In order to be efficient, it is necessary that the following aspects should taken into consideration in the utilization of this method:

- Students (performers) should have clearly formed in their minds the structure of the whole motor action.

- The exercise of the component parts of the motor action should be achieved until their appropriate acquisition, not their becoming automatic.

- The combined execution should not be attempted until the component parts have been properly acquired.

- The duration of the exercise should correspond to the physical characteristics of the performers.

- The component elements of the motor action should be executed in their natural succession.

The methodical procedure of integral learning is used for the acquisition and the formation of simple and easy motor skills, which do not impose their decomposition.

\section{Conclusions}

In the educational-training process from the military organisation the trained skills are integrated in complex systems of activities typical for leading fight actions.

In this context, the movable skills need to be trained, fixed and improved durably because, unless they are not perfected they can disautomatize losing their value.

Irrespective of the degree of difficulty, motor skills demand an appropriate execution throughout their formation in order to be efficient in the formative process.

It is also extremely important that the mistakes should be eliminated during execution before the automation of movement is achieved. The formation, consolidation and improvement of motor and utility-applicable skills specific to military physical education represents a useful and efficient modality for the organization of support in learning and for ensuring the actional capacity of fighters.

\section{References}

1. DRAGNEA, A., TEODORESCU, MATE, S., Teoria sportului, Editura Fest, Bucureşti, 2002.

2. EPURAN, M. , HORGHIDAN, V., Psihologia educaţiei fizice, Bucureşti, A.N.E.F.S., 1994.

3. FLOCA, M., Forţele de elită ale lumii, Editura Militară, Bucureşti, 1999.

4. HARRE, D., LEOPOLD, W., Rezistenţa - forţa şi antrenamentul de rezistenţă forţa în sportul de performanţă. Theorie und praxis der Korpenkultur, Berlin, 35, 1986, $267 / 1987$. 